BBA 7 IOO9

\title{
Change in $\mathrm{Na}^{+}$uptake during amino acid transport
}

In some of their early studies, CHRISTENSEN et al.$^{1,2}$ found that a net efflux of $\mathrm{K}^{+}$, and a partial replacement of intracellular $\mathrm{K}^{+}$by $\mathrm{Na}^{+}$, accompanied uptake of amino acids by Ehrlich ascites cells and that concentrative uptake was inhibited by the replacement of extracellular $\mathrm{Na}^{+}$by $\mathrm{K}^{+}$or choline. Subsequently RIGGS, WALKER AND CHRisTENSEN ${ }^{3}$ suggested that uptake of amino acids by Ehrlich ascites cells depended on intracellular $\mathrm{K}^{+}$levels. However, the results of Hempling and Hare ${ }^{4}$ did not fit this hypothesis and KROMPHARDT et al..$^{5}$ found that glycine uptake depended on extracellular $\mathrm{Na}^{+}$, not intracellular $\mathrm{K}^{+}$. WHEELER et al. ${ }^{6}$ have reevaluated the work of Riggs, Walker AND Christensen ${ }^{3}$ and now conclude that the results actually gave evidence for a dependence of amino acid flux on the $\mathrm{Na}^{+}$gradient. This reinterpretation agrees with the hypothesis of VIDAVER ${ }^{7}$ who suggested that the $\mathrm{Na}^{+}$gradient is coupled to and energetically drives amino acid uptake in the pigeon red blood cell.
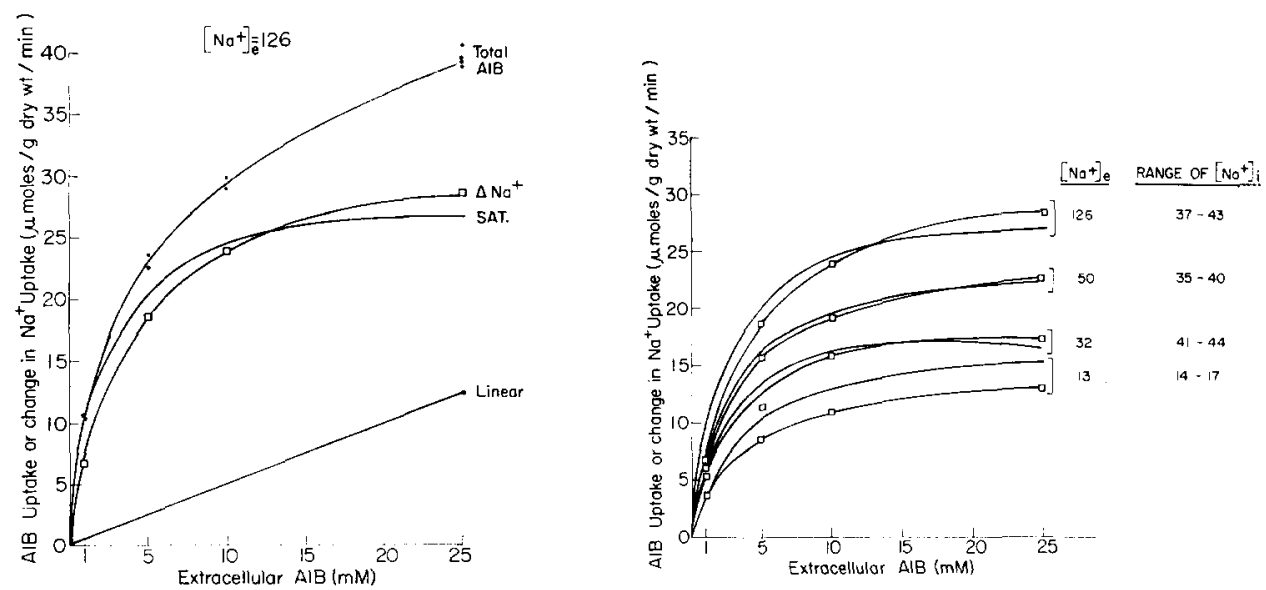

Fig. I. Correlation of change in $\mathrm{Na}^{+}$uptake with $\alpha$-aminoisobutyric acid (AIB) uptake for I-min incubations at $37^{\circ}$. Uptakes were measured for initial extracellular $\alpha$-aminoisobutyric acid concentrations of $\mathrm{I}, 5$, ro and $25 \mathrm{mM}$. Change in Na+ uptake (the curve designated by $\square$ and $\triangle \mathrm{Na}^{+}$) is the difference between $\mathrm{Na}^{+}$uptake in the presence of $\alpha$-aminoisobutyric acid and the uptake in the absence of $\alpha$-aminoisobutyric acid. The curve labeled SAT. is the saturatable component of $\alpha$-aminoisobutyric acid uptake calculated by subtracting the linear component from the total $\alpha$-aminoisobutyric acid uptake.

Fig. 2. Correlation of change in $\mathrm{Na}^{+}$uptake with the saturatable component of $\alpha$-aminoisobutyric acid (AIB) uptake at different extracellular sodium concentrations for I-min incubations at $37^{\circ}$. Uptakes were measured with initial extracellular $\alpha$-aminoisobutyric acid concentrations of $\mathbf{I}, 5$, Io and $25 \mathrm{mM}$. The change in $\mathrm{Na}^{+}$uptake $(\square-\square)$ and the saturatable $\alpha$-aminoisobutyric acid uptake (plots with no associated symbol) were calculated as described for Fig. I. The extracellular and intracellular concentrations of $\mathrm{Na}^{+}$are in mequiv/l of extracellular and mequiv $/ \mathrm{kg}$ of intracellular water. 
The critical question now is whether $\mathrm{Na}^{+}$actually enters the cell along with the amino acid or whether it merely participates in some secondary reaction accompanying transport. This same problem has been the focus of recent research on transport in the intestine. $\operatorname{CSAKY}^{8}$ has shown that sodium is necessary for active intestinal transport of amino acids, and SCHULTZ AND ZALUSKY ${ }^{9}$ have shown that the flux of $\mathrm{Na}^{+}$from mucosal to serosal surface and the short-circuit current increase when alanine is transported and suggest a $I: I$ stoichiometry between the two on the basis of their finding of a Michaelis-Menten type of relation between the increase in short-circuit current and the alanine concentration on the mucosal side. They further suggest that a ternary complex, $\mathrm{Na}^{+}$-amino acid -carrier is involved in the intestinal transport of amino acids, and that the transport is driven by the $\mathrm{Na}^{+}$gradient. The same hypothesis had been proposed by CRANe, Miller AND BIhleR ${ }^{10}$ for sugar transport in the intestine.

We have attacked this problem directly by measuring the simultaneous uptakes of ${ }^{3} \mathrm{H}$-labeled $\alpha$-aminoisobutyric acid and of ${ }^{22} \mathrm{Na}^{+}$for incubation times of I min at $37^{\circ}$ for a series of different extracellular concentrations of $\mathrm{Na}^{+}$and $\alpha$-aminoisobutyric acid. The methods and procedures used have been described previously ${ }^{11,12}$. For this study the Ehrlich ascites cells were not subjected to osmotic shock. We have found a I:I relationship between the increase in $\mathrm{Na}^{+}$uptake and the saturatable component of $\alpha$-aminoisobutyric acid uptake. Fig. I shows that when the linear component of the $\alpha$-aminoisobutyric acid uptake (referred to as the $\mathrm{Na}^{+}$-insensitive component by INUI AND CHRISTENSEN ${ }^{13}$ ) is subtracted the remaining, saturatable and $\mathrm{Na}^{+}$-sensitive, uptake of $\alpha$-aminoisobutyric acid is approximately the same as the increase in $\mathrm{Na}^{+}$uptake. As is shown in Fig. 2, this I:I relationship holds over a wide range of extracellular concentrations of $\mathrm{Na}^{+}$and $a$-aminoisobutyric acid, for both inwardly and outwardly directed $\mathrm{Na}^{+}$gradients. The intracellular and extracellular $\mathrm{Na}^{+}$levels are given in Fig. 2 for each set of curves. In the experiment in which the extracellular $\mathrm{Na}^{+}$was $32 \mathrm{mM}$ and intracellular $\mathrm{Na}^{+}$was in the range $4 \mathrm{I}-44 \mathrm{mM}$ the $\alpha$-aminoisobutyric acid uptake in I min was not concentrative at the higher levels of $\alpha$-aminoisobutyric acid but at I $\mathrm{mM} \alpha$-aminoisobutyric acid the intracellular conconcentration reached was $2 \mathrm{mM}$. Thus these experiments provide direct evidence for a I:I stoichiometry between $\alpha$-aminoisobutyric acid and $\mathrm{Na}^{+}$uptake as well as evidence against the hypothesis that the $\mathrm{Na}^{+}$gradient is the sole source of the energy for the transport of $\alpha$-aminoisobutyric acid.

We have run similar experiments with $\mathrm{L}$-phenylalanine which is taken up almost entirely by the $\mathrm{Na}^{+}$-insensitive $\mathrm{L}$ system and have found no increase in uptake of $\mathrm{Na}^{+}$accompanying uptake of L-phenylalanine.

We interpret our results as indicating that one $\mathrm{Na}^{+}$is bound to the carrier of the $\mathrm{Na}^{+}$-sensitive A system but that no $\mathrm{Na}^{+}$is bound to the carrier of the $\mathrm{Na}^{+}$-insensitive $\mathrm{L}$ system. It is unlikely that the $\mathrm{Na}^{+}$is moving independently as a counter-ion of $\alpha$-aminoisobutyric acid because both $\alpha$-aminoisobutyric acid and phenylalanine are neutral amino acids and one would then expect it to move with phenylalanine as well as with $\alpha$-aminoisobutyric acid. Hence if it is moving as a counter-ion it must be as a counter-ion for the carrier for $\alpha$-aminoisobutyric acid. Although our experiments do not exclude this possibility it seems to us that by far the most likely explanation of the $\mathrm{I}: \mathrm{I}$ stoichiometry and the Michaelis-Menten type of relationship between the $a$-aminoisobutyric acid flux and the extracellular concentration of 
sodium $^{13}$ is that the sodium and the $a$-aminoisobutyric acid are bound to the same carrier.

This investigation was supported by U.S. Public Health Service Research Grant No. CA o6734 from the National Cancer Institute.

Department of Physiology,

JAMES A. SCHAFER

The University of Michigan,

Ann Arbor, Mich. (U.S.A.)

JOHN A. JACQUEZ

I H. N. Christensen and T. R. Riggs, J. Biol. Chem., I94 (I952) 57.

2 H. N. Christensen, T. R. Riggs, H. Fischer and I. M. Palatine, J. Biol. Chem., i98 (I952) I.

3 T. R. Riggs, L. M. Walker and H. N. Christensen, J. Biol. Chem., 233 (1958) i 479.

4 H. G. Hempling and D. HaRe, J. Biol. Chem., 236 (I96I) 2498.

5 H. Kromphardt, H. Grobecker, K. Ring and E. Heinz, Biochim. Biophys. Acta, 74 (I963) 549.

6 K. P. Wheeler, Y. Inui, P. F. Hollenberg, E. Eavenson and H. N. Christensen, Biochim. Biophys. Acta, Iog (I965) 620.

7 G. A. Vidaver, Biochemistry, 3 (I964) 795.

8 T. Z. Csaky, Fedevation Proc., 22 (1963) 3.

9 S. G. Schultz and R. Zalusky, Nature, 205 (I965) 292.

io R. K. Crane, D. Miller and I. Bihler, in H. Kotyk and A. Kleinzelier, Symp. on Membrane Transport and Metabolism, Academic Press, New York, I96I, p. 439.

i I J. A. Schafer and J. A. Jacquez, Biochim. Biophys. Acta, I35 (1967) 74 I.

I2 J. A. Jacguez, Biochim. Biophys. Acta, I35 (1967) 75 I.

i 3 Y. Inui and H. N. Christensen, J. Gen. Physiol., 5o (ig66) 203.

Received June 23rd, I967

Revised manuscript received September 6th, I967

Biochim. Biophys. Acta, $135(1967)$ 1081- 1083

BBA 71007

\section{An electron spin resonance signal in brain microsomes}

Microsomal preparations from liver and adrenal cortex have been examined by ESR spectroscopy ${ }^{1-5}$. Studies on brain microsomes with this technique have not been reported.

Active cation transport and ATPase activity have been studied extensively, in brain as well as in other tissues ${ }^{6}$. A connection between microsomal electron transport and the active transport of ions has been suggested (e.g. refs. 6-8), but experimental evidence has been lacking. Previous work ${ }^{9,10}$ using frog skin suggested that unpaired electrons participate in active cation transport. We report here preliminary findings showing that a free radical is in some way connected with microsomal ATPase.

Rats were killed by decapitation after light ether anesthesia. (One preparation from rats that received no ether was also examined; we observed no difference in the signal.) The brains were quickly removed and chilled. The microsomal pellet was

Abbreviation: ESR, electron spin resonance. 